\title{
EFFECT OF IONIC CONCENTRATIONS AND pH ON THE ATTERBERG LIMIT OF COHESIVE SOIL
}

(Received 3 February 2020; Revision Accepted 9 March 2020)

\begin{abstract}
The addition of salt to pore water can affect the behaviour of the soil by influencing the electrochemical forces exist between the solid, liquid and dissolved phases. Changes in geotechnical behaviour of fine grained soils under the influence of ionic concentrations and $\mathrm{pH}$ depends on the chemistry of the soil constituents and the pore fluid chemistry. The geotechnical modifications of soil behaviour largely depend on the clay particles and the diversities in the nature of the clay types is due to their specific surface and the net electrical charge on them. Generally, clay particles surface are negatively charged while its edges are positively charged. To preserve electrical neutrality the negative charge of the clay particle is balanced by the attraction of cations which are held between the layers, and on the surface of the particles. The charged clay surface together with the counter-ions in the pore water at the diffuse double layer. The present study focuses on the effect of the ionic concentrations of potassium chloride (KCl) and $\mathrm{pH}$ on the liquid limit of fine grained soil. Fall cone test was conducted to measure the liquid limit in different concentrations of the pore fluid, with each of the ionic concentrations prepared in four different $\mathrm{pH}$ values $(3.5,5.5,7.5$ and 9.5). From the test results, it was observed that the $\mathrm{pH}$ values generally has no significant effect on the liquid limit of the samples; while the liquid limit lightly undulated at lower $\mathrm{pH}$ values at ionic concentrations of $0.00001 \mathrm{M}, 0.0004$ $\mathrm{M}$ and $0.003 \mathrm{M}$, the $\mathrm{pH}$ values had least influence at higher ionic concentrations $(0.1 \mathrm{M}$ and $1.8 \mathrm{M})$ of $\mathrm{KCL}$. This behaviour is attributed to the buffering effects of the relatively high solute content at $0.1 \mathrm{M}$ and $1.8 \mathrm{M}$. On the other hand, the liquid limit decreased with increasing ionic concentrations of KCL. Increasing the ionic concentration reduces the thickness of the diffuse double layer thereby depleting the repulsive forces and hence increases the effective stress leading to flocculation of clay particles that gave rise to the reduction in the liquid limit of the clayey sample
\end{abstract}

KEYWORD: Liquid Limit, potassium chloride, pore fluid, ionic concentrations, $\mathrm{pH}$

\section{INTRODUCTION}

Cohesive soils are fine-grained, low-strength, and easily deformable soils that have a tendency for particles to adhere. Soil is classified as cohesive if the amount of fines (silt and clay-sized material) exceeds $50 \%$ by weight (Mitchell and Soga 2005). Cohesive soils have significant cohesive strength and exhibit plasticity. Cohesion between soil particles comes from three major sources, cementation, electrostatic and electromagnetic attraction, and primary valence bonding and adhesion (Mitchell and Soga 2005). Soil structure which is influenced by Interparticle force, refers to the geometric arrangement of soil or mineral particles and depends on genetic, chemical, mineralogical characteristic, as well as past stress conditions of the soil. The study of fine-grained soils is important to geotechnical engineering, agriculture, construction, medicine and materials science.
The most commonly and naturally occurring fine grained material is clay, which behaviour depends on particle size, shape, particle size distribution, surface chemistry, surface area, surface charge and pore fluid chemistry. Of recent, due to population growth, progressive living standard, and industrial progress, much of the air, water, and land have become polluted. Open dumps, chemical and industrial wastes, and many other sources cause these problems. All types of pollution have direct or indirect effects on ground soil properties.

A good number of researches have been conducted to understand the influence of pore water chemistry on the strength characteristics of fine-grained soils, while little has been done to understand the effects of $\mathrm{pH}$, especially acidic water, despite the fact that acid contamination has become an increasing concern around the world. Generally, changes in the geotechnical behaviour of fine grained soils under the

E. Ike, Department of Physics, Modibbo Adama University of Technology, P. M. B. 2076, Yola, Adamawa State, Nigeria. 
influence of inorganic salts depend on the composition of the soil and the pore fluid chemistry, whose source may be through natural processes such as weathering of mudstone (indigenous) or due to activities such as municipal waste storage, accidental spills, or acidic rains (anthropogenic sources). This problem has been recognized recently, and a few studies have been performed to investigate the effects of pore fluid chemistry in the light of $\mathrm{pH}$ and ionic concentrations on soil properties (Harun et al., 2015). Yet the effect of pore fluid $\mathrm{pH}$ and ionic concentrations on the strength of soil remains unclear. During rains, water infiltrates into the waste and reacts physically, chemically and biologically with the waste to produce leachate. The leachate infiltrates into the ground causing subsoil and ground water contaminations. Generally, the solid waste continues to stay at the location where it is placed over the years, hence the process of leachate infiltration into the subsurface environment continues, slowly and for several years. Liquid wastes also seep into the subsurface soil and contaminate the subsurface soil and the ground water. Such industrial effluents either treated or untreated are discharged over the soil which may change the properties of soil. Therefore, it becomes very imperative to understand the effect of industrial effluents. Peradventure there is an improvement in engineering behavior of soil, there sure going to be a value addition to the industrial wastes serving the benefits of safe disposal of effluent. However, if the constant degradation of the engineering behavior of soil persists, then solution for decontamination is to be thought of.

For residual top soils, salts may be present in natural condition depending on the source rock. Ocean surge cause occasional flooding in coastal area with salt water leading to an increase in salt minerals into soil. Metallic elements are also present in greater amount in mining areas (Davies, 1971). The disposal of solid, liquid wastes or effluents over the land leads to degradations and alterations in the physical and mechanical properties of the soil (Matthew, 2014). Modification of soil properties causing foundation failure, structural damage in light industrial buildings on soil contaminated by various industrial effluents has been reported. Sometimes the soils may be lacking the geotechnical properties for soil to be used as construction materials, which are to be stabilized using additives; sometimes good enough soil can get contaminated by industrial wastes which become severely affected to be used at all. Then these need decontamination.

According to Ajam et al., (2015) the engineering characteristics of fine-grained soils, particularly clayey soils are influenced by a range of factors including density, porosity, and structure, as well as the history of tension and granulation, type of clayey minerals and plastic property. The engineering characteristics are also influenced by the type of minerals and the volume of these minerals in the pore water (Essays, 2018). This suggests that any change in these characteristics will lead to a corresponding change in the physical and mechanical characteristics of the soil. Engineering properties such as density, shear strength and the plasticity of soil are important as these properties affect the structural performance of the soil particularly under foundations and in geotechnical engineering vis-a-vis civil engineering applications. In basic engineering theory on soil mechanics, it is commonly assumed that the pore water and solid particles are chemically inert, in other words there is no chemical interaction between the different phases. However, Ajam et al., (2015) point out that the surface of clayey mineral particles is negatively charged which means that electrochemical forces exist between the solid, liquid and dissolved phases which influences the mechanical behaviour of clayey soil. In addition, it is known that the quantity and nature of electro-chemical forces depends on the type of anion and cation in exchange phase and the impact of this interaction on the cation exchange capacity. Ajalloeian et al., (2013) make the point that the properties of water used in construction activities such as mixing concrete is governed by regulations and international standards, however there are fewer standards, governing the properties of water used in works associated with soil for example in the construction of earthen dams. Yet there is evidence to suggest that some minerals such as salt can affect the mechanical properties of soil. Bouksila et al., (2008) suggest that the impact of the salinity on the soil is dependent on the solubility of the soil. Suganya and Sivapullaiah (2015) argue that the behaviour of the soil is dependent on the microstructure which in turn can be influenced by the water content and the chemical content of that water. Lolaev et al., (1997) suggests that the temperature of the soil and the chemical content of the salt can influence the bonds between particles within the micro-structure which in turn affects the engineering properties of the soil. Chaney and Demars (1985) point out that salt in pore can affect soil behaviour particularly in leaching which in a slope can lead to a landslide.

In this study, we seek to shed more light on this topic by providing experimental data on the variations in liquid limit of our clay sample subjected to pore fluids at different ionic concentrations of $\mathrm{KCl}$ and $\mathrm{pH}$. The $\mathrm{KCl}$ concentrations were prepared in five different concentrations $(0.00001 \mathrm{M}, 0.0004 \mathrm{M}, 0.003 \mathrm{M}, 0.1 \mathrm{M}$ and 1.8 M), each of these was prepared in four different $\mathrm{pH}$ values of $3.5,5.5,7.5$ and 9.5.These values represent the $\mathrm{pH}$ that exist in the groundwater under normal conditions otherwise there will be dissolution of the clay minerals, thereby preventing a reasonable interpretation of the results.

\section{LITERATURE REVIEW}

There have been studies to investigate the impact of ionic concentrations and $\mathrm{pH}$ of pore fluid on the engineering properties of the soil, including shear strength and classification of the soil, ideally using Atterburg limits. The preceding review focuses on the study of different soils and the impact of salinity on the engineering properties of the soil, stating the type tests conducted in the review alongside the results obtained as this will be useful in building background information for the tests conducted in the present study and for making informed comparison cum analysis the data derived from the test.

Yukselen-Aksoy et al., (2008) conducted Liquid limit, Shrinkage limit and Plastic limit test to study the behavior of clays with addition of seawater. The test results were analysed and found that the effects of seawater are on the tested consistency limits and compressibility characteristics of soils when they have liquid limits up to $110 \%$. 
Shariatmadari et al., 2011 studied the effect of three inorganic salts, $\mathrm{KCl}, \mathrm{CaCl}_{2}$ and $\mathrm{MgCl}_{2}$ on some geotechnical properties of a commonly used clay soil in impermeable bottom barrier in Kahrizak landfill. Also the effect of bentonite content on these properties was investigated. The liquid limit results indicate that using salt solutions as pore fluids decreases the liquid limit of the mixtures. Furthermore by increasing salt concentration in both mixtures, the liquid limit decreases. Increasing the salt concentration and the cation valence decreases the interparticle repulsion which results in particles moving more freely in lower water contents, thus the liquid limit of the mixtures decreases.

Seracettin et al., (2008) experimentally studied the effects of 4 different salt solutions on the consistency limits of clays. The salt solutions used as leachate compounds were ammonium chloride $(\mathrm{NH} 4 \mathrm{Cl})$, potassium chloride (KCl), copper(II) sulphate (CuSO4), and iron(II) sulphate (FeSO4). Consistency limit tests were conducted on low plasticity ( $\mathrm{CL}$ class) and high plasticity (CH-class) commercial clays using both distilled water and these salt solutions. The experimental results indicated that the liquid limit increased when the salt concentration for the $\mathrm{CL}$ clay was increased. Moreover, the liquid limit was found to decrease when the salt concentration for the $\mathrm{CH}$ clay was increased.

Yukselen-Aksoy (2008) studied the Seawater effect on consistency limits and compressibility characteristics of clays. The consistency limits includes limit, plastic and shrinkage limits, sediment volume and compressibility characteristics of ten soils were tested using distilled water and natural seawater from the Aegean Sea. The results indicate that the effect of seawater is negligible on the tested consistency limits and compressibility characteristics of soils when they have liquid limits up to $110 \%$. The seawater effect is most noticed on the consistency limits and compressibility of Na-bentonites. All reported data were normalized by dividing the index values obtained using seawater by those obtained using distilled water. The comparison of the data indicate that the compiled data and present study data are in good agreement; when the normalized values are plotted as function of liquid limit, all index properties plot along the unity line until the liquid limit of soils is about $110 \%$; then, the normalized index values decrease almost linearly with liquid limit.

Chittaranjan et al., (2011) studied effect of sea water on some geo-technical properties of clayey soil. Soil which falls under high plasticity $(\mathrm{CH})$ group is used and it is observed that the liquid limit, plastic Limit and plasticity index values of the contaminated soil increases when the result of tap water is compared with the result of sea water. The liquid limit increase $9.32 \%$, plastic limit Increase $8 \%$ and plasticity index Increase $10.91 \%$.

Ivasuc (2012) investigated the influence of seawater on the behavior of the expansive clays. The four clayey soil samples were gathered with different mineralogy and plasticity characteristics and tested to determine liquid limit in the presence of distilled water, tap water and seawater. The results showed that the liquid limit decrease in presence of seawater; values of all liquid limits in seawater are lower than those in tap water. This difference can be seen more clearly for the bentonite sample.

Investigation was carried out by Sivapullaiah et.al.
(2005) to determine the effect of $\mathrm{NaOH}$ solution on some geotechnical properties of soil with low plasticity (LL 38\%). Their results have shown that the liquid limits of soil increases as the $\mathrm{NaOH}$ solution concentration increases. There as on behind that is the formation of a new swelling compound created by reaction of alkali solution with clay.

Studies were conducted on the effects of phosphate ions $\left(\mathrm{PO}^{-3}\right)$ on index properties by Sreepada Rao, (1982). Phosphate adsorption increases the liquid limit, of kaolinite and liquid limit of Na-montmorillonite decreased on phosphate adsorption. In Camontmorillonite, initially these values decreased with treatment, but subsequently increased. The treatment appreciably changed the physico-chemical properties of both kaolinite and montmorillonite clays, Phosphoric acid increases stable aggregation leading to higher porosities and water holding capacities but lower bulk densities. Phosphate adsorption increases the liquid limit, the surface area and the free swell volumes of kaolinite significantly because of flocculation of clay particles. Because of aggregation, the liquid limit of $\mathrm{Na}-$ montmorillonite decreased on phosphate adsorption. In Ca-montmorillonite, initially these values decreased with treatment, but subsequently increased because of the exchange of divalent calcium by monovalent hydrogen Effect of four salt solutions including $\mathrm{NH}_{4} \mathrm{Cl}, \mathrm{KCl}, \mathrm{CuSO}_{4}$ and $\mathrm{FeSO}_{4}$ on consistency limits of low plasticity (CL) clay and high low plasticity $(\mathrm{CH})$ clay was studied by Arasan and Yetimoglu (2008). The conclusions were as follows: For CL clay, the liquid limits and plastic limits increased with increase in salt concentrations up to 0.2 M. The salt solutions at a concentration greater than 0.2 $M$ seemed to damage the clay fabric. All the salt solutions with a concentration up to approximately $0.2 \mathrm{M}$ significantly reduced the liquid limits of $\mathrm{CH}$ class clay. For $\mathrm{NH}_{4} \mathrm{Cl}$ and $\mathrm{KCl}$ concentrations greater than around $0.2 \mathrm{M}$, the liquid limit of $\mathrm{CH}$ clay remained more or less constant. However, for $\mathrm{FeSO}_{4}$ and $\mathrm{CuSO}_{4}$ metallic salts the liquid limit of $\mathrm{CH}$ clay tended to increase at concentration higher than $0.2 \mathrm{M}$. For $\mathrm{CH}$ clay plastic limit decreased at low salt concentrations (between 0.0001 and $0.001 \mathrm{M}$ ) and then increased with increase in salt concentration between $0.001 \mathrm{M}$ and $0.2 \mathrm{M}$. For concentration value higher than $0.2 \mathrm{M}$, the plastic limit was not significantly affected by salt solutions and plastic limit value approached the raw clay sample. Both $\mathrm{CL}$ and $\mathrm{CH}$ clays flocculated and formed clusters as the clay class tended to be changed. For the conditions investigated, $\mathrm{CL}$ and $\mathrm{CH}$ class clays were transformed into $\mathrm{ML}$ and $\mathrm{MH}$ class soils respectively according to Unified Soil Classification System (USCS), (2000; 2006). Investigation was done to see the effect of different chloride compounds such as $\mathrm{KCl}, \mathrm{CaCl}_{2}$ and $\mathrm{MgCl}_{2}$ on various geotechnical properties by Tamadher et. al., (2007). According to them liquid limit, plastic limit and plasticity index decreases with increase of salt content A study was conducted by Rassou et. al., (2013) to show the effect of saline water on geotechnical properties of fine grained soil. They used three types of water, distilled, saline and half saline water. They reported that Atterberg limits decreased as the water salinity increases for CL soil.

In another study Ayininuola, G. M, and Agbede, O. A (2013) focused on the influence of 3 inorganic salts viz. Sodium Chloride $(\mathrm{KCl})$, Potassium Nitrate, $\left(\mathrm{KNO}_{3}\right)$ and 
Calcium Sulphate $\left(\mathrm{CaSO}_{4}\right)$ in various concentrations on liquid limits and plastic limits of 2 sub-soils. The limits were monitored before and after contamination. The soil cation exchange capacity (CEC), exchangeable cations and exchangeable anions were also determined. A set of equations for predicting $\mathrm{LL}$ and $\mathrm{PL}$ at different level of chemical interaction with time was developed using multiple regression analysis model. The results showed that both $\mathrm{KCl}$ and $\mathrm{KNO}_{3}$ brought about reduction in $\mathrm{LL}$ and PL.

Mishra et al., 2008, studied the effect of Atterberg's limit and observed that in liquid limit where soil moisture is higher, the effect of salinity will be more. The liquid limit gradually decreases with the increase in the salt concentrations.

Fatahi et. al., (2011) studied the Atterberg's limit on various kaolinite, bentonite and sand mixtures using salt water, the results indicated that the liquid limit of kaolinite clay decreases with increase in salinity. For pure kaolinite an increase in water salinity from 0 to $200 \mathrm{gm} /$ liter $\mathrm{KCl}$, results in $6 \%$ decrease in Liquid limit. Similarly, the bentonite showed same as of kaolinite clay. Nearly $50 \%$ and $70 \%$ of decrease in liquid limit occurs with $20 \%$ and $5 \%$ salt concentration increase for kaolinite and bentonite respectively.

Ivasuc et al., (2012) studied the seawater influence on the behavior of the expansive clays. In

this study, four clayey soil samples were gathered with different mineralogy and plasticity characteristics were tested to determine liquid limit in the presence of distilled water, tap water and seawater. The results showed that the liquid limit decrease in presence of seawater; values of all liquid limits in seawater were lower than those in tap water and the difference is seen more clearly in Bentonite sample.

Mahmoud et. al., (2013) experimented on the effect of salinity of groundwater on the geotechnical properties of some Egyptian clay. The test results showed the effect of groundwater salinity on the tested samples. The plasticity index decreased from 26 for pure water clay soil to 24.96 for clay soil mixed with $80 \%$ salt. Ajalloeian et.al., (2013) found that the Atterberg limits decreased due to the presence of saline water on fine grained soil as opposed to tap water.

Mahmoud et. al., (2016) studied the effect of Atterberg's limit on expansive clayey sample, where the sample is passed through Distilled water, tap water, treated waste water and seawater. The results showed a clear change in the liquid after using different water types in mixing with expansive clay soils. It has been observed that there wss a significant change in liquid limit due to use of different water samples. Liquid limit decreases from $70 \%$ by using distilled water to $68 \%, 61 \%$ and $55 \%$ when using tap water, treated waste water and sea water, respectively.

\section{MATERIALS AND METHODS}

Locally available clayey soils were collected from a site in Sangere village, Girei Local Government Area, Nigeria; it lies between Latitude $9^{\circ} 11^{1} 15^{11} \mathrm{~N}$ and longitude $12^{\circ} 20^{1} 29^{11} \mathrm{E}$. The sitesituates along the YolaMaiduguri highway and share border with Modibbo Adama University of Technology (formerly Federal University of Technology Yola), to the East and about $4 \mathrm{~km}$ away from Girei town, the Girei Local Government headquarter. The apparatus used were lump crusher, sieves sizes of $2 \mathrm{~mm}$ to $150 \mathrm{~mm}$ to remove stones, coarse and large particles such as pebbles and dirt. Dryers of 120 to $170{ }^{\circ} \mathrm{C}$ were also provided to dry the crushed and sieved samples. Mortar was equally provided to ground the treated clay samples to powder. Digital weighing balance (Model: CAS SW-1S) was provided for measuring mass. A systematic experimental programme was carried out to study the variation in Atterberg Limits with ionic concentrations of potassium chloride and $\mathrm{pH}$, using the fall cone equipment (Model: NL SCIENTIFIC Model NL 5047 X / 001).

The British Fall Cone Test Standard (British Standard $1377,1990)$ defines the liquid limit as the water content at which an $80 \pm 0.05 \mathrm{~g}$ stainless steel cone with a $30 \pm 1^{\circ}$ angle penetrates a re-molded soil $20 \mathrm{~mm}$ specimen when the cone is released at the soil surface. The liquid limit is the water content boundary dividing the plastic and liquid behavioural states of clays. The shear strength of clay at its liquid limit depends on the clay fabric, as particles or aggregates interact to supply the resistance to shear (Mitchell, 1993). Penetration measurements were taken with a cone penetrometer at four moisture contents for each re-molded mineral mixture.

The clay sample was washed with deionized water until the Electric Conductivity was less than $100 \mu \mathrm{S} / \mathrm{cm}$. The first moisture content was obtained by mixing $60-80 \mathrm{~mL}$ of electrolyte solution with $200 \mathrm{~g}$ of the clay soil. The clay mixture was allowed to hydrate over night before obtaining the first measurement point. After the equilibration time, the clay was thoroughly re-mixed and carefully placed in a metal cup, $6.25 \times 4.5 \mathrm{~cm}$. Efforts were made to avoid vacuum inside the mineral mixture. The excess material was scraped off the top leaving a smooth even surface. Once an acceptable penetration depth is recorded $(14 \mathrm{~mm}-28 \mathrm{~mm}), 15 \mathrm{~g}$ of the soil were removed to determine the moisture content. The pore-fluid $\mathrm{pH}$ was measured using the centrifuge. The remaining clay was then mixed with additional fluid volume to increase the moisture content for the next penetration measurement.

The results of the moisture content $\mathrm{W}(\%)$, the moisture content corresponding to $20 \mathrm{~mm}$ penetration was determined as the liquid limit for each of ionic concentrations of $\mathrm{KCl}(0.00001 \mathrm{M}, 0.0004 \mathrm{M}, 0.003 \mathrm{M}$, $0.1 \mathrm{M}$ and $1.8 \mathrm{M}$, with each of the ionic concentrations prepared in 3.5, 5.5, 7.5 and $9.5 \mathrm{pH}$ values) and cone penetration $(\mathrm{mm})$ are presented below 


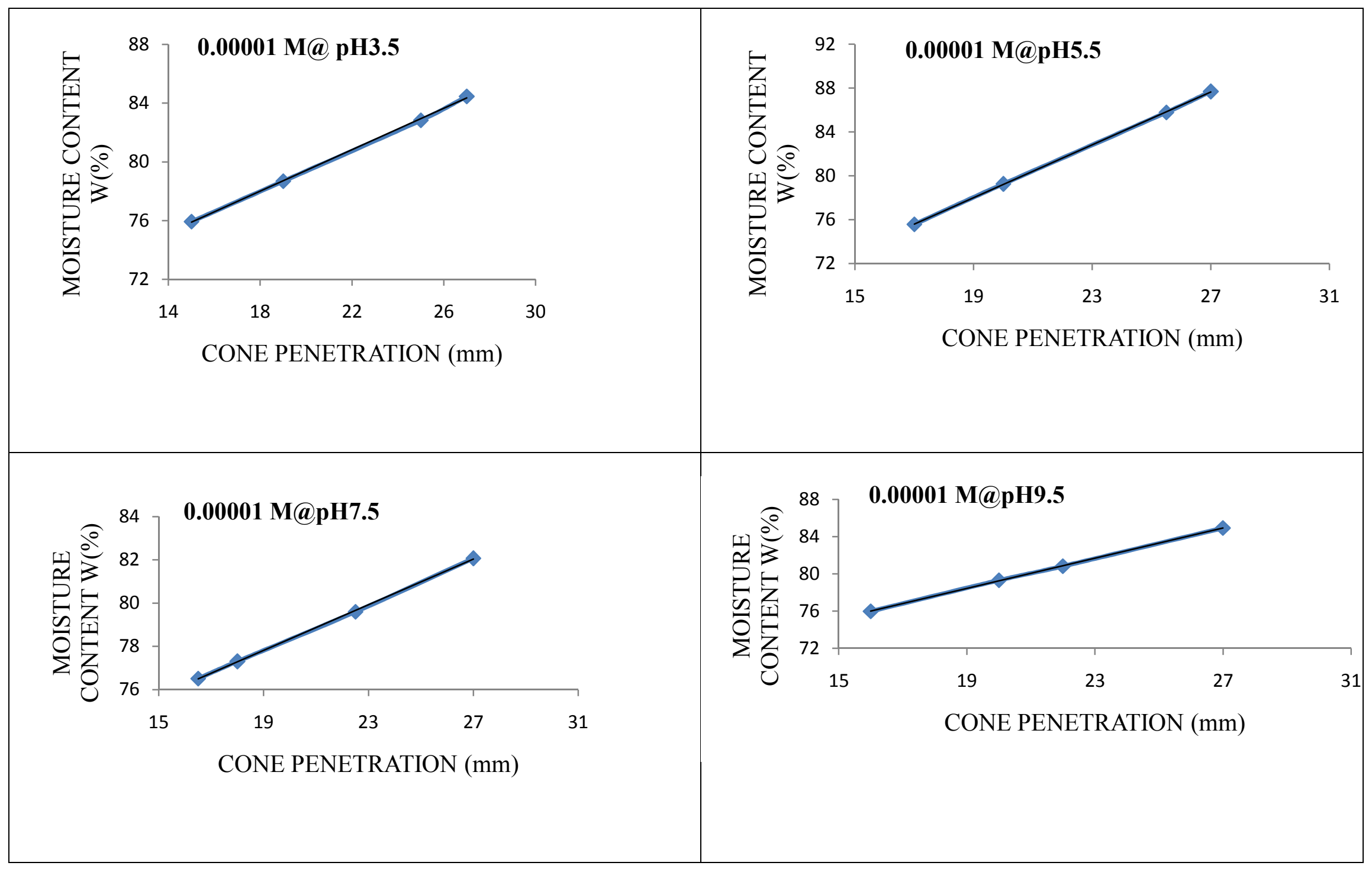

Figure 1: Moisture content versus cone penetration for $0.00001 \mathrm{M}$ of $\mathrm{KCl}$ solution 


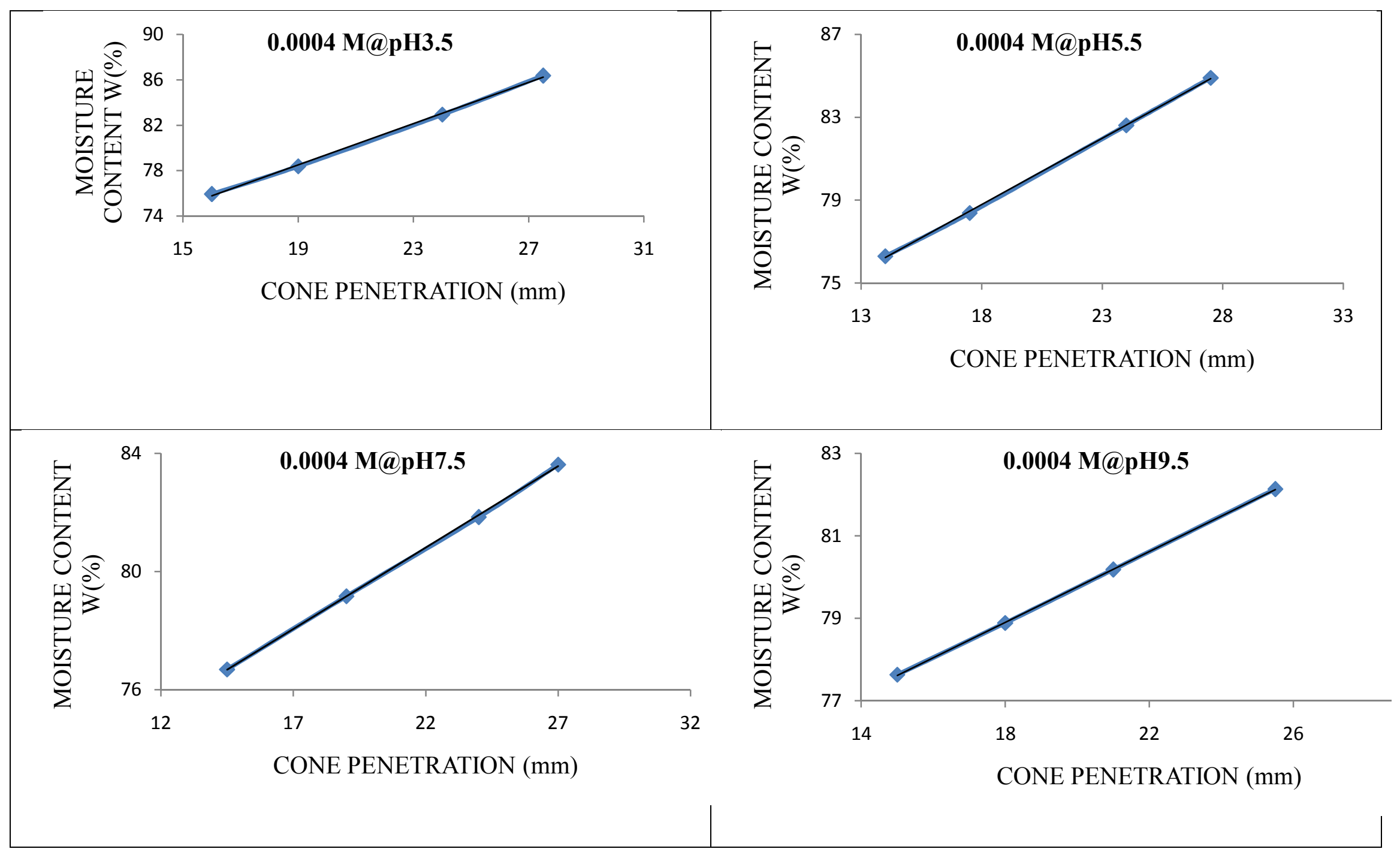

Figure 2: Moisture content versus cone penetration for $0.00001 \mathrm{M}$ of $\mathrm{KCl}$ solution 


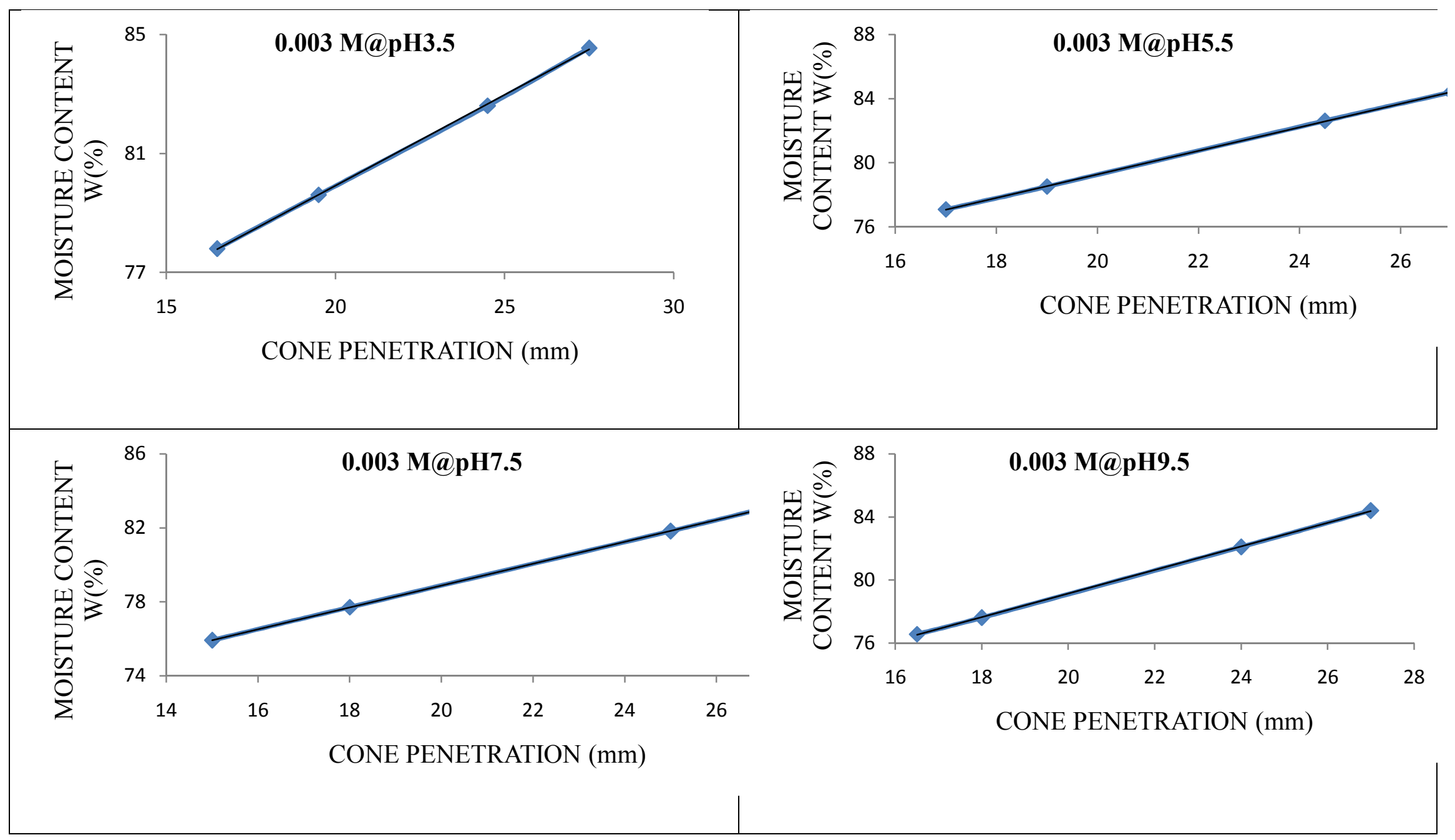

Figure 3: Moisture content versus cone penetration for $0.00001 \mathrm{M}$ of $\mathrm{KCl}$ solution 

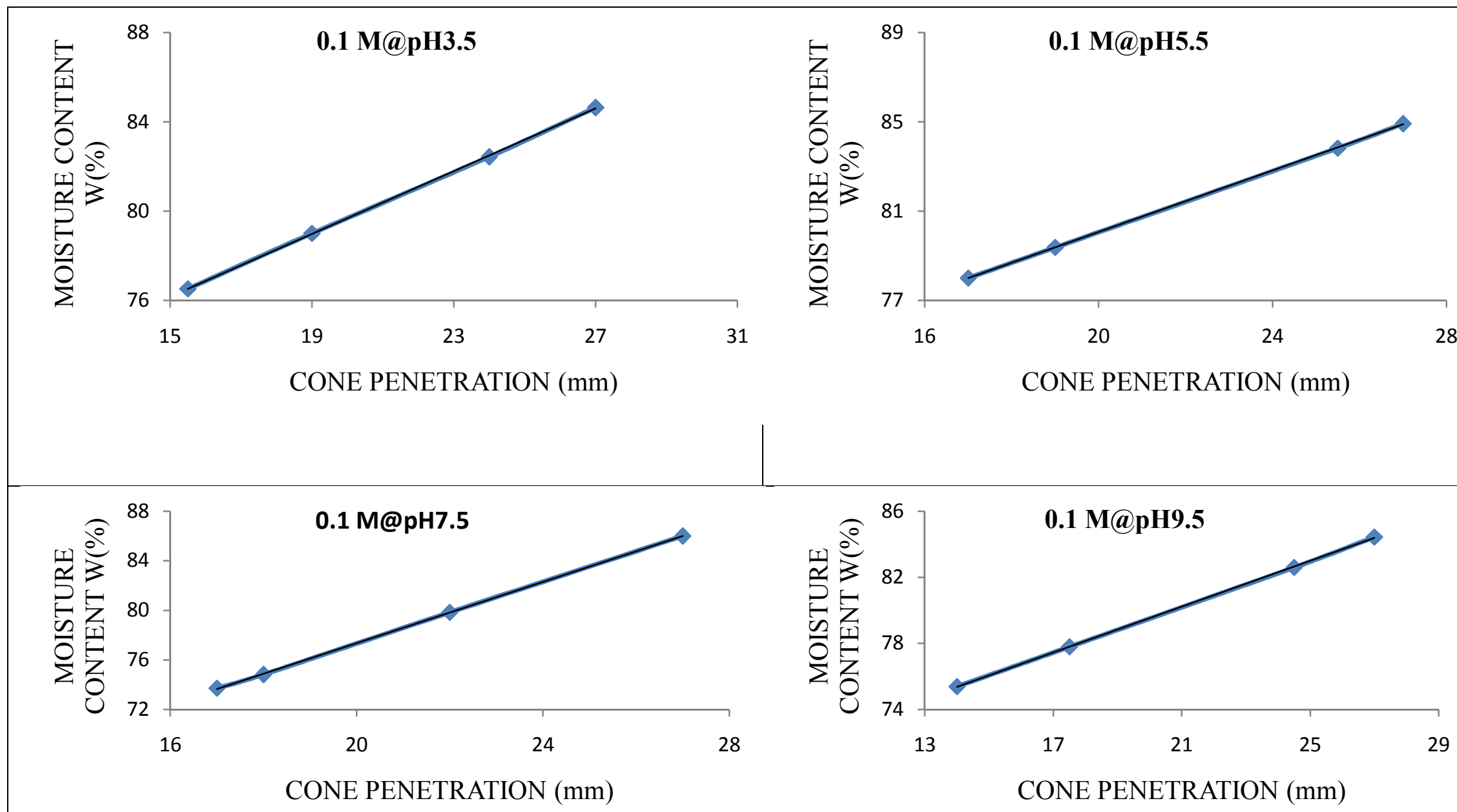

Figure 4: Moisture content versus cone penetration for $0.00001 \mathrm{M}$ of $\mathrm{KCl}$ solution 


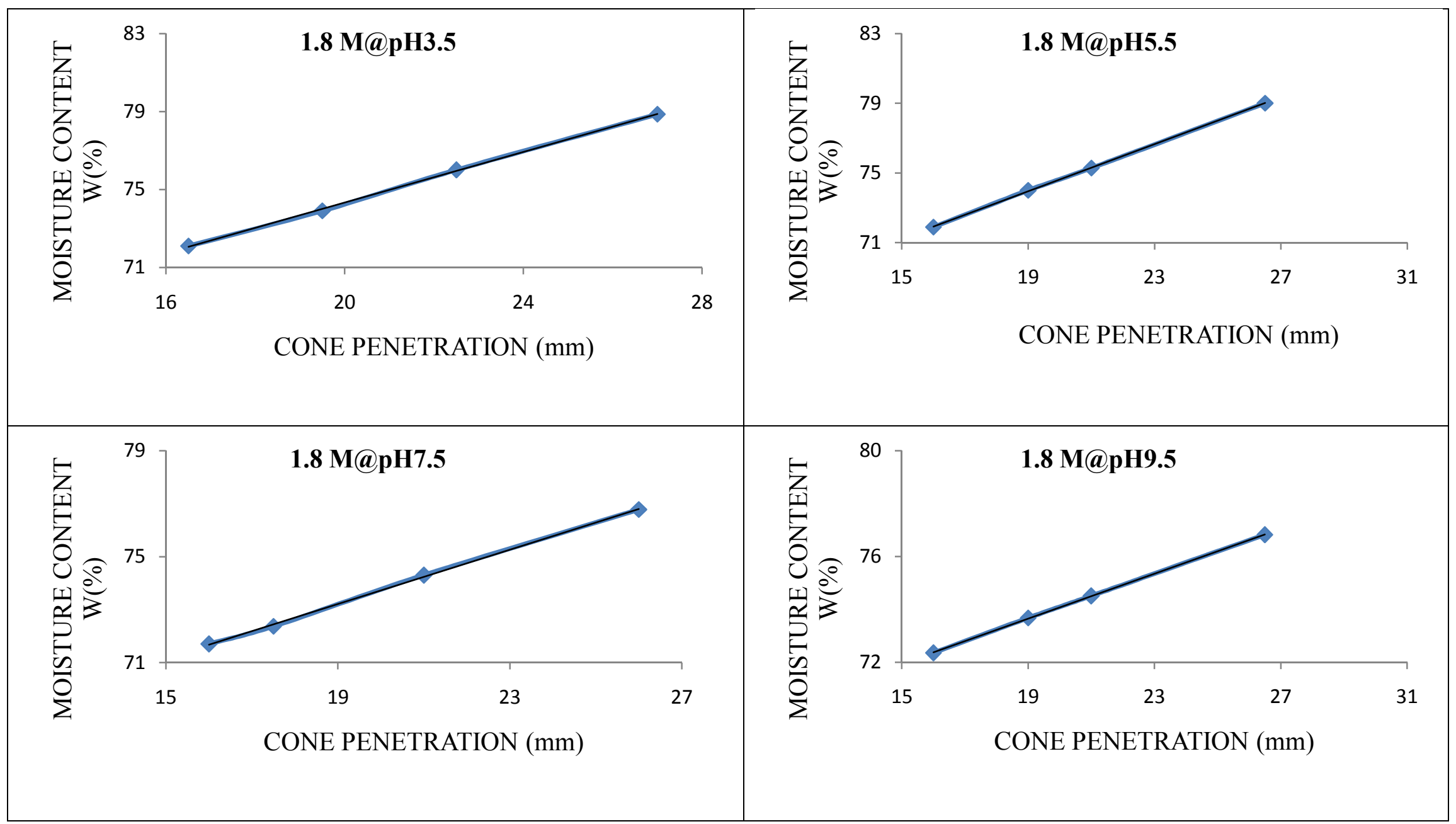

Figure 5: Moisture content versus cone penetration for $0.00001 \mathrm{M}$ of $\mathrm{KCl}$ solution 
Figure 6: Liquid Limit versus pH

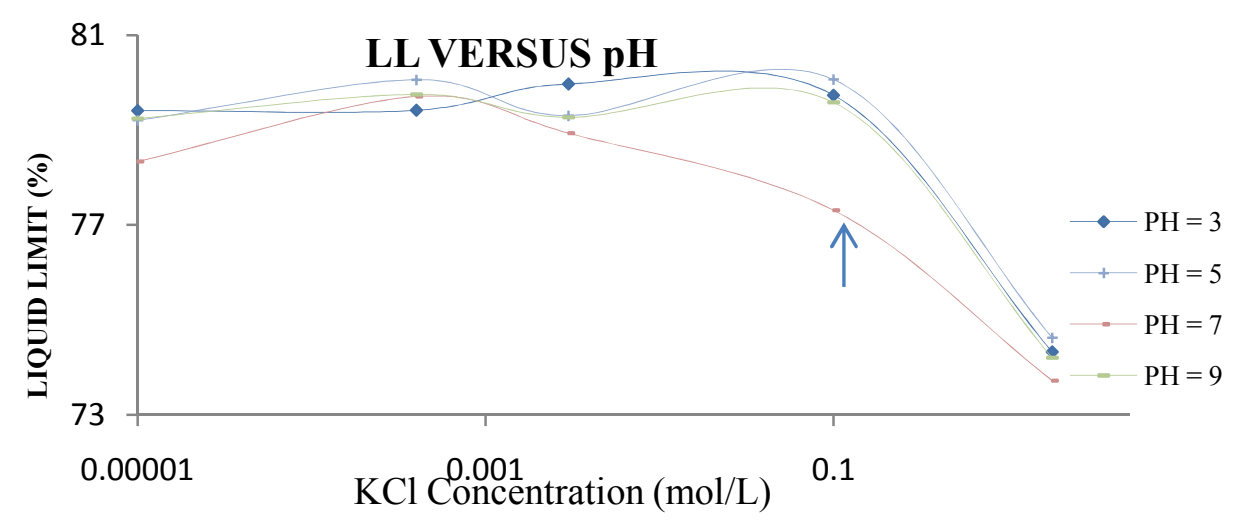

\section{LL VERSUS pH}

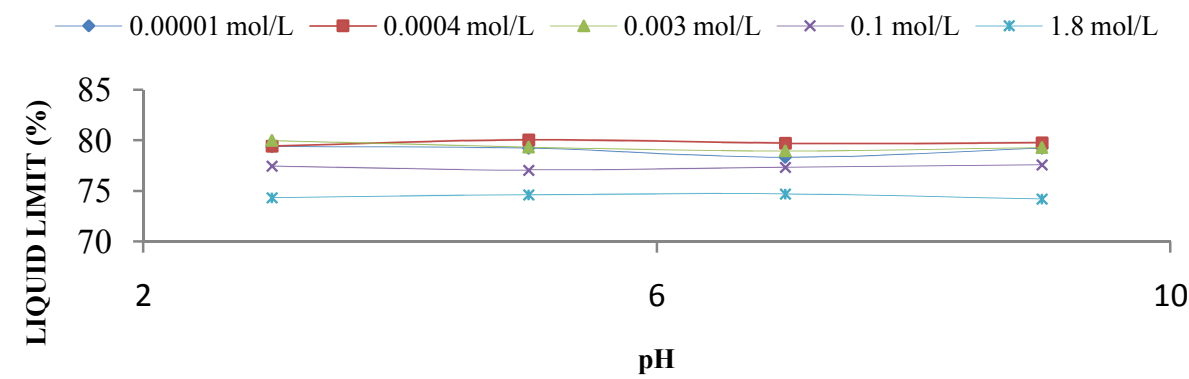

Figure 7: Liquid Limit versus lonic concentrations of $\mathrm{KCl}$ 
The change in soil behaviour at particular state can be explained by the nature of water at microstructure level of clay minerals (Khamehchiyan, 2007). Water molecule is dipole and the opposite charges of water will attract to the opposite charges of the clay minerals (Das, 1994). Dipolar water is attracted with the negatively charged surface of clay particles and also by the cations in the double layers. Clay minerals and water molecules have a tendency to attract each other and subsequently influence the double layers.

The test results is shown in figures 1-7 above, for accuracy of results, the different moisture contents were plotted against the corresponding cone penetration values (figures 1-6), a line of best fit was drawn between the points obtained and the moisture content corresponding to the penetration of $20 \mathrm{~mm}$ was obtained as the liquid limit. The graph plots show a direct relationship between water content and cone penetration depths.

The addition of acid or base $(\mathrm{pH})$, although these both affect the ionic strength, but did not have much effect on the Liquid Limit of the sample especially across the $\mathrm{pH}$ values especially at ionic concentrations of $0.00001 \mathrm{M}$, $0.0004 \mathrm{M}, 0.003 \mathrm{M}$ (Figure 6). However, the liquid limit line flattens out for all $\mathrm{pH}$ values at relatively higher ionic concentrations of $0.1 \mathrm{M}$ and $1.8 \mathrm{M}$, this is due to the buffering effect of the clay sample as are result of the increased solute content. As shown in Figure 6, changes in $\mathrm{pH}$ did not give rise to any significant differences in the Liquid Limit, as the Liquid Limit remained fairly constant. This same trend is consistent with the findings by van Paassen (2004).

From Figure 7, it can be observed that the decrease in the liquid limit due to the increased ionic concentrations did not generate any major effect in the liquid limit of the sample at ionic concentrations of $0.00001 \mathrm{M}, 0.0004 \mathrm{M}$ and $0.003 \mathrm{M}$, but a further increase in the ionic concentrations $(0.1 \mathrm{M}$ and $1.8 \mathrm{M})$ decreased the liquid limit significantly. This behaviour can be explained in terms of the interparticle forces. For clay paste at the liquid limit, the forces of interaction between clay particles become sufficiently weak so as to make for easy movement of particles relative to each other. Increasing the salt concentration decreases the interparticle repulsion and porosity (Santamarina et al., 2002; Palomino and Santamarina, 2005) hence encourages particle flocculation, which results in particles moving more freely in lower water contents/ interparticle distance (Warkentin 1961; Sridharan and Rao 1975) in the soil microstructure, resulting in the decrease of the liquid limit. This result is in agreement with studies by previous researchers (Sridharan et al., 1986; Di Maio, 1996; Klein, 1999; Palomino and Santamarina, 2005) and is generally attributed to the shearing resistance at the particle level, changes in diffuse double layer thickness and fabric changes. When the thickness of the diffuse double layer decreases, the liquid limit of the soil will also reduce (Sidharan, 1975). The diffuse double layer is a region on the clay particle surface at the interface with water consisting of two layers; the partial charge surface and the diffuse layer of cations (Holtz et al., 2011; Mitchell and Soga, 2005). Increases in electrolyte concentration reduces the surface potential under the condition of a constant surface charge, the thickness of the diffuse double layer decreases (Mitchell and Soga, 2005), and the liquid limit of clay is reduced.

\section{CONCLUSION}

The engineering characteristics of fine-grained soils, particularly clayey soils are influenced by factors such as density and porosity, structure, type of minerals and plastic properties. Any change in these characteristics will ultimately change the physical and mechanical characteristics of the soil. The addition of salt to pore water can affect the behaviour of the soil by influencing the electrochemical forces exist between the solid, liquid and dissolved phases. This study focuses on the effects of ionic solutions percolations on the geotechnical behavior of clayey soil. Though the influence of pore fluid chemistry on the engineering behaviour of clay soil is still controversial but geotechnical behaviours can be explained in terms of diffuse double layer thickness. By increasing the ion concentration, the thickness of diffuse double layer decreases which leads to flocculation of the clay particles.

\section{REFERENCES}

Anandhanarayanan G. and Murugaiyan V, Effects of Salt solutions and Sea Water on the geotechnical property of soil-A Review, IJERT, Vol.3 Issue 3, march-2014.

Ajam, M., Sabour, M. R. and Dezvareh, G. A., 2015. Study of water salinity effect on geotechnical behavior of soil structure using response surface method (RSM), (Case study: Gotvand Dam). Ciencia and Natura, 37, pp.350-359.

Ajalloeian, R., Mansouri, H. and Sadeghpour, A.H., 2013. Effect of Saline Water on Geotechnical Properties of Fine-grained Soil. Electronic Journal of Geotechnical Engineering, 18, pp.1419-1436.

ASTM D4318-98. Standard test methods for liquid limit, plastic limit, and plasticity index of soils. Annual book of ASTM standards, American Society for Testing and Materials, Philadelphia.

ASTM Standard D2487, 2000., Standard Practice for Classification of Soils for Engineering Purposes (Unified Soil Classification System)," ASTM International, West Conshohocken, PA, 2000,DOI: 10.1520/D2487-00, www.astm.org.

Ayininuola, G.M., and O.A. Agbede, 2013. Influence of Inorganic Salts on Soils Liquid and Plastic Limits. , 15(1), pp.51-60.

Behzad Fatahi, HadiKhabbaz and Sudip Basack. 2011., Effects of Salinity and Sand Content on Liquid Limit and Hydraulic Conductivity". Australian Geomechanics Vol 4668 No 1.

Bouksila, F., Perrson, M., Berndtsson, R. and Bahrii, A., 2008. Soil water content and salinity determination using different dielectric methods in saline gypsiferous soil. Hydrological Sciences Journal, 53:1, 253-265. 
Chaney, R. C. and Demars, K. R., 1985. Strength Testing of Marine Sediments: Laboratory and In-situ Measurements: a Symposium Sponsored by ASTM Committee D-18 on Soil and Rock, San Diego, CA, 26-27 Jan. 1984, Issue 883. New York: ASTM International.

Chittaranjan, M. T. Srikanth, B. Yamini Lakshmi and D. Pavani 2011. Effect of sea water on some geo technical properties of clayey soil" International Journal of Earth Sciences and Engineering 1ISSN 0974- 5904, Volume 04, No 06 SPL.

D 2487 - 06: Standard Practice for Classification of Soils for Engineering Purposes (Unified Soil Classification System) (PDF) (Technical report). ASTM International. 2006.

Davies B. E., 1971. Trace Element Content of Soils Affected by Base Metal mining in the West of England, Oikos, 22, 366-372.

Das B. M., 1994. Principle of Geotechnical Engineering, 3rd edition, PWS Publishing Company, 436 pp.,

DI Maio C., 1996. Exposure of bentonite to salt solution: osmotic and mechanical effects. Géotechnique, 46, n. 4, pp. 695-707.

Essays, UK. November 2018. Pore Water Salinity in a Clay Soil Sample. Retrieved from https://www.ukessays.com/services/exampleessays/engineering/pore-water-salinity-in-aclay-soil-sample.php?vref=1

Fatahi, BehzadandKhabbaz, Hadiand Basack, Sudip 2011. Effects of Salinity And Sand Content On Liquid Limit And Hydraulic Conductivity. Australian Geomechanics Journal. 46. 67-76.

Harun, S. N., Ali Rahman, Z., Rahim, S. A., Lihan, T. and Idris, W. M. R., 2015. Effects of Leachate on Geotechnical Characteristics of Sandy Clay Soil. The 2013 UKMFST Postgraduate Colloquium AIP Conf. Proc. 1571, 530-536 (2014); doi: 10.1063/1.4858709.

Holtz R. D., Kovacs W. D, SheahanT. C., 2011. An Introduction to Geotechnical Engineering. Pearson Education, United States of America. ISBN: 0132496348, 9780132496346.

Ivasuc T., 2012. Seawater influence on the behavior of the expansive clays. Vol. I,

Khamehchiyan, M., Charkhabi, Amir and Tajik, Majid., 2007. Effects of crude oil contamination on geotechnical properties of clayey and sandy soils. Engineering Geology. 89. 220-229. 10.1016/j.enggeo.2006.10.009.

Klein, K., 1999. Electromagnetic properties of high specific surface minerals. PhD thesis, Georgia Institute of Technology, Atlanta, Georgia, USA, $335 \mathrm{pp}$.
Lolaev, A. B., Shklyarov, N. D. and Lyalina, O. A., 1997. Effects of salts on physical and mechanical properties of frozen soils. Engineering Geology and the Environment in Marinos, G. (ed.) Engineering Geology and the Environment, Volume 1. Boca Raton: CRC Press, pp.215220.

Mahmoud M. Abu Zeid A, Ahmed K. Abd El-Aal 2016. Effect of Salinity of Groundwater on the Geotechnical Properties of Some Egyptian Clay". 1110-0621 Production and Hosting by Elsevier B.V. On behalf of Egyptian Petroleum Research Institute.26. 10.1016/j.ejpe.2016.09.003.

Matthew A. G., 2014. Journal of earth sciences and geotechnical engineering, vol. 3, pp 37.

Mohamed Mahmoud A. Hussein 2016. Effect of Different Water Types on Expansive Soil Behavior, Life Science Journal; 13 (5).

Mitchell, J. K., 1993. Fundamentals of Soil Behavior. John Wiley and Sons, New York, 437 pp.NaderShariatmadari $1,{ }^{*}$,

Marzieh Salami2, Mehran Karimpour Fard. 2011. Effect of inorganic salt solutions on some geotechnical properties of soil-bentonite mixtures as barriers. International Journal of Civil Engineering, Vol. 9, No. 2, June 2011.

Mishra, A. K., Ohtsubo, M., Li, L. Y., Higashi, T., and Park, J., 2008. Effect of salt of various concentrations on liquid limit, and hydraulic conductivity of different soil-bentonite mixtures. Environmental Geology, 57(5), 1145-1153. doi:10.1007/s00254-008-1411-0.

Mitchell J. K. and Soga K., 2005. Fundamental of Soil Behaviour. Third edition, Wiley, Hoboken, New Jersey.

Otoko G. R., 2014. "The Effect of Salt Water on the Physical Properties, Compaction Characteristics and Unconfined Compressive Strength of a Clay, Clayey Sand and Base Course". European International Journal of Science and Technology Vol. 3 No. 2.

Palomino, A. M., and Santamarina, J. C., 2005. "Fabric map for kaolinite: Effects of $\mathrm{pH}$ and Ionic concentration on behavior," Clays and Clay Minerals, Vol. 53, No3, pp.211- 223.

Rassoul A., Hadiseh M. and Amir H. S., 2013. Effect of Saline Water on Geotechnical Properties of Fine-grained Soil" Vol. 18.

Santamarina, J. C., Klein, K. A., Palomino, A. and Guimaraes, M. S., 2002. Micro-scale aspects of chemical-mechanical coupling $\ddot{y}$ interparticle forces and fabric. Pp. $47 \ddot{y} 64$ in: Chemical Behaviour: Chemo-Mechanical Coupling from 
Nano-Structure to Engineering Applications (C

Di Maio, T. Hueckel, and B. Loret, editors).

Seracettin ARASAN and Temel yet" Imoglu 2008. Effect of inorganic salt solutions on the consistency limits of two clays.Turkish J. Eng. Env. Sci. 32 $2008,107-115$.

Shariatmadari, N., M. Salami and M. Karimpour Fard 2011. Effect of Inorganic Salt Solutions on Some Geotechnical Properties of SoilBentonite Mixtures as Barriers. International Journal of Civil Engineering, Vol., 9.

Sivapullaiah, P., and H. Manju 2005. Kaolinite-Alkali Interaction and Effects on Basic Properties. Geotech. Geol. Eng., 23, 601-214.

Sreepada Rao, A., 1982. Physico Chemical Properties and Engineering Behaviour of Anion Adsorbed Clay, Ph.D.Thesis, Indian Institute of Science, Bangalore.

Sridharan, A. and Rao, G.V., 1973. Mechanisms controlling volume change of saturated clay and the role of effective stress concept, Geotechnique, 23:3 , 359-382.
Sidharan A., 1975. Mechanism Controlling the Liquid Limit of Clays, Proceeding of Istanbul Conference on SM and F.E., Istanbul

Sridharan A., Rao S.M., Murthy N.S. 1986 - Liquid limit of Montorillonite soils. Geotechnical Testing Journal, 9, n. 3, pp. 156-159

Suganya, K. and Sivapullaiah, P.V., 2015. Effect of changing water content on the properties of Kuttanad soil. Geotechnical and Geological Engineering,33(4), pp.913-921.

Tamadher T. A. Anuar B. K., Zamri B. C., 2007. stabilisation of silty clay soil using chloride compounds. Journal of Engineering Science and Technology Vol. 2, No. 12007 102-110

Van Paassen, L. A., 2004. The influence of pore fluid salinity on consolidation behaviour and undrained shear strength development of clayey soils. MSc Thesis, TU Delft.

Warkentin, B.P. 1961. Interpretation of the upper plastic limit of clays, Nature, 190, 287-288.

Yukselen-Aksoy Y, Kaya A, Ören AH 2008. Seawater effect on consistency limits and compressibility characteristics of clays. Eng Geol 102(1):5461. https://doi.org/10.1016/j.enggeo.2008.07.00 5 
